\title{
Transglutaminases in Crohn's disease
}

\author{
G D'Argenio, L Biancone, V Cosenza, N Della Valle, F P D'Armiento, M Boirivant, \\ F Pallone, G Mazzacca
}

\begin{abstract}
Transglutaminases are a family of Cadependent enzymes involved in various biological events. Circulating transglutaminase (factor XIIIa) is decreased in blood of patients with inflammatory bowel diseases. There is evidence that factor XIIIa and tissue type transglutaminase, present in cell cytosol, bind to various proteins of the extracellular matrix. This study examined the value of serum transglutaminase assay in the treatment and follow up of Crohn's disease and then investigated the intestinal location of both forms of transglutaminases by immunohistochemistry in normal and abnormal tissues. Serum transglutaminase activity was assayed in 36 patients with active Crohn's disease (CDAI>150). Eighteen patients were studied prospectively from relapse into remission. A significant inverse correlation $(p<0.001)$ was found between circulating transglutaminase and Crohn's disease activity index; a correlation was also found between serum transglutaminase and serum orosomucoid $(p<0 \cdot 01)$ and $C$ reactive protein $(p<0 \cdot 01)$. Patients were prospectively studied until clinical remission showed improvement in both their CDAI score mean (SD) (230 (46) to 72 (34), $\mathbf{p}<0.01)$ and transglutaminase activity mean (SD) $(0.61 \quad(0.12)$ to $0.93 \quad(0.13)$ $\mathrm{mU} / \mathrm{ml}, \mathrm{p}<0 \cdot 01)$. The immunohistochemistry assessment showed a colocalisation of factor XIIIa and tissue transglutaminase to the extracellular matrix of damaged tissues. In conclusion, these data confirm the value of serum transglutaminase assay as marker of Crohn's disease activity, extend the utility of serum transglutaminase assay to follow up of the disease, and emphasised the role of different types of transglutaminases in extracellular matrix assembly in the damaged tissues.

(Gut 1995; 37: 690-695)
\end{abstract}

Keywords: Crohn's disease, activity index, tissue transglutaminase, factor XIII, tissue repair.

Transglutaminases mediate covalent cross linking between proteins by forming amide bonds between the $\gamma$-carboxamide groups of peptide bond glutamine moieties and the $\epsilon$-amino groups of specific peptide bond residues. ${ }^{1}$ At least three genetically distinct forms of transglutaminases are known. Factor XIII (FXIII) is a plasma circulating haemostatic factor that represents an inactive form of transglutaminase. ${ }^{2}$ Besides FXIII, a tissue transglutaminase that is present in cell cytosol of all tissues and organs, ${ }^{3}$ and a membrane bound epidermal transglutaminase ${ }^{4}$ present in keratinocytes have been described. As the final enzyme in the coagulation cascade, activated FXIII (FXIIIa) catalyses the intermolecular cross linking of fibrine chains to each other and to other haemostatic proteins. ${ }^{5}$ The enzyme activity can be detected in Ca-activated plasma (FXIIIa) ${ }^{6}$ and in serum after clot formation (serum transglutaminase). ${ }^{7}$ FXIII circulates in blood as a heterotetrameric zymogen $\left(a_{2} b_{2}\right)$ composed of two enzymatically active a-subunits and two b-subunits as carrier proteins. ${ }^{8}$ Tissue transglutaminase participates in various processes such as programmed cell death, ${ }^{9}$ wound healing, ${ }^{10}$ and cell growth and differentiation. ${ }^{11} 12$ Evidence is mounting that both tissue transglutaminase and FXIIIa bind to fibronectine and other extracellular proteins contributing to the wound healing process. ${ }^{1013-15} \mathrm{We}$ found serum transglutaminase activity reduced in various intestinal disorders: coeliac disease with relation to the active and remission phases, ${ }^{16}$ and widespread intestinal malignancies (for example, intestinal lymphoma and $\alpha$-chain disease). ${ }^{17}$ Circulating enzyme activities have also been found decreased during the acute phase of inflammatory bowel disease and they were strongly related to the activity indices. ${ }^{6} 7$ Recently we showed in a rat model of chronic colitis that serum and tissue transglutaminase activities reflect the changed intestinal morphofunctional integrity suggesting that serum transglutaminase assay could be a simple marker of intestinal mucosal status in inflammatory bowel disease. ${ }^{18}$ The clinical activity of Crohn's disease is based on clinical and laboratory evaluations representing the sum of scores from several variables (for example, CDAI and Harvey-Bradshaw score), ${ }^{19}$ 20 which do not always reflect the pathogenic processes taking place in the intestine. In a recent endoscopic study in Crohn's disease, Modigliani et al show that mucosal inflammation and ulceration may be present in patients with symptomatically quiescent disease. ${ }^{21}$ In view of these findings, this study was performed with two main objectives. The first was to discover if serum transglutaminase assay could be useful in the treatment and follow up of Crohn's disease. The second objective was to investigate by immunohistochemistry the intestinal location of tissue transglutaminase and FXIIIa both in normal and abnormal mucosa in Crohn's disease.

\section{Methods}

Patients

Thirty six patients with active Crohn's disease newly diagnosed at the gastrointestinal unit of
'Federico II', via Pansini 5 , 80131 Naples, Italy.

Accepted for publication 23 March 1995 
TABLE I Clinical and laboratory summary of study group

\begin{tabular}{lccc}
\hline Crohn's patients & & Ileitis & Ileocolitis/colitis \\
\hline Patients (n) & 36 & 15 & 21 \\
Male & 16 & 9 & 13 \\
Female & 20 & 6 & 8 \\
Age (mean (SD)) & 40 & $40 \cdot 7(8 \cdot 1)$ & $38 \cdot 3(20 \cdot 3)$ \\
CDAI & $233(49)$ & $228(37)$ & $236(57)$ \\
Serum transglutaminase mean (SD) & $0 \cdot 62(0 \cdot 11)$ & $0 \cdot 72(0 \cdot 14)$ & $0 \cdot 50(0 \cdot 08)$ \\
Packed cell volume mean (SD) (\%) & $37(8)$ & $38 \cdot 8(6 \cdot 2)$ & $37 \cdot 5(3 \cdot 5)$ \\
White blood count mean (SD) (mm (m) $\left.^{3}\right)$ & $10 \cdot 1(3 \cdot 2)$ & $9 \cdot 9(2 \cdot 1)$ & $10 \cdot 3(4 \cdot 2)$ \\
Albumin mean (SD) (g/d) & $3 \cdot 7(0 \cdot 50)$ & $3 \cdot 6(0 \cdot 40)$ & $3 \cdot 5(0 \cdot 7)$ \\
Orosomucoid mean (SD) (mg/dl) & $134(56)$ & $147(60)$ & $103(33)$ \\
Sedimentation rate mean (SD) (mm/h) & $31(19)$ & $42(25)$ & $38(28)$ \\
C reactive protein mean (SD) (mg/dl) & $3 \cdot 0(3 \cdot 9)$ & $2 \cdot 8(3 \cdot 5)$ & $3 \cdot 9(4 \cdot 1)$ \\
& & & \\
\hline
\end{tabular}

the University 'La Sapienza' of Rome were included in the study. The disease was confined to the distal ileum in 15 patients and to the colon with or without ileal involvement in 21 patients. Four patients with Crohn's disease of the ileum had bowel resection because of failure of medical treatment. The surgical procedure was ileocaecal resection with side to side ileocolonic anastomosis in all patients. In no patients did histological assessment show inflammation at the resection margins. The Crohn's disease group included 20 women and 16 men with a mean age of 40 years (range 19-72).

Disease activity was assessed by the Crohn's Disease Activity Index (CDAI), ${ }^{19}$ supplemented by laboratory measurements. The CDAI score was evaluated in each patient on the day of blood collection for transglutaminase activity assay. Serum C reactive protein was measured by an electroimmunodiffusion technique, ${ }^{22}$ orosomucoid by nephelometry ${ }^{23}$; the erythrocyte sedimentation rate was measured by the Westergren method. ${ }^{24}$ Blood packed cell volume and white blood cell counts were performed by a Coulter counter and serum albumin concentrations by a colorimetric method. ${ }^{25}$
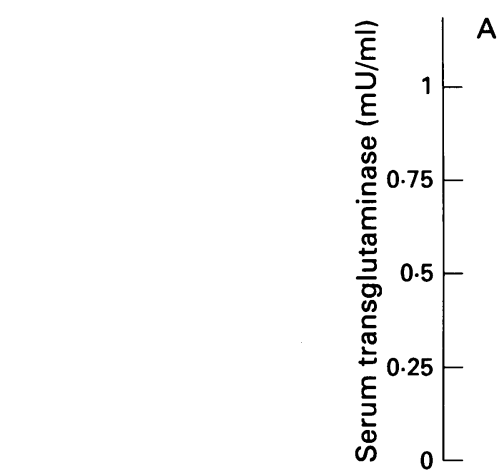

Figure 1: Serum transglutaminase $(A)$ and $C D A I$ score (B) in Crohn's disease patients with ileal or ileocolonic/colonic disease involvement.

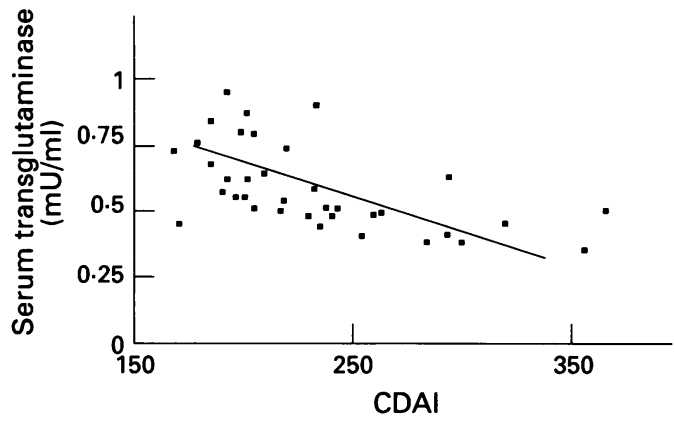

Figure 2: Correlation between serum transglutaminase and $C D A I$ score in active Crohn's disease patients $(\mathrm{r}=-0.62$, $n=36, p<0.001$ ).

Serum transglutaminase and haematological parameters were also evaluated in 18 patients studied prospectively during the active phase $(\mathrm{CDAI}>150)$ and subsequent inactive phase $(\mathrm{CDAI}<150)$ of the disease.

In the four patients undergoing surgery, serum transglutaminase concentrations and haematological parameters were evaluated before and 15 and 60 days after bowel resection.

The control group included 21 patients with disease other than inflammatory bowel disease but also leading to debility (liver cirrhosis, cardiovascular disorders, non-intestinal malignancies). Serum transglutaminase from 38 healthy subjects was also assayed.

\section{Transglutaminase activity}

Venous blood samples were collected after an overnight fast and left at room temperature for two hours to avoid the influence of coagulation. Serum samples were stored at $-20^{\circ} \mathrm{C}$ until the assay. Transglutaminase activity on serum was assayed using a modified method of Lorand et al ${ }^{2627}$ : $30 \mu$ l of the sample were added to $45 \mu$ l of reaction mixture containing a final concentration of $0.25 \mathrm{mM}$ of ${ }^{14} \mathrm{C}$ putrescine (Amersham, UK), $50 \mathrm{mM}$ of dithiothreitol, $10 \mathrm{mM}$ of $\mathrm{CaCl}_{2}$, and $4 \%$ (w/v) dimethylcasein in TRIS-HCl buffer $(50 \mathrm{mM})$ pH 9.0 with $0.1 \%$ Triton $\mathrm{X} 100$ and incubated in a shaking bath at $37^{\circ} \mathrm{C}$ for 20 minutes. Twenty $\mu \mathrm{l}$ were spotted onto $3 \mathrm{MM}$ Whatman round paper filters $(2 \mathrm{~cm})$ and immediately plunged into $10 \%$ ice cold trichloroacetic acid for 15 minutes. Two consecutive 15 minutes washings were performed in $5 \%$ ice cold trichloroacetic acid followed by a brief washing in ethanol-acetone $(50 \% \mathrm{v} / \mathrm{v})$ and then in acetone. The dried paper filters were counted in $6 \mathrm{ml}$ of Aquasure scintillant (Dupont-NEN). A similar procedure was adopted for blanks, standards, and controls. Transglutaminase units were expressed as $1 \mathrm{mU}=1 \mathrm{nmol}$ of putrescine into acceptor protein at $37^{\circ} \mathrm{C}, \mathrm{pH} 9$.

\section{Western blotting}

Tissue transglutaminase from guinea pig liver (Sigma, St Louis, MO) and purified FXIIIa (gift from Behring, Marburg, Germany) were run on SDS/polyacrylamide gels according to 
the method of Laemmli, ${ }^{28}$ and than transferred to nitrocellulose with Biorad transblot apparatus. The nitrocellulose was blocked by incubation with $3 \%$ bovine serum albumine in TTBS (50 mM TRIS, pH 7.9, $150 . \mathrm{mM}$ $\mathrm{NaCl}$ and $0.05 \%$ TWEEN 20). Primary antibodies, anti-tissue transglutaminase (generously given by $\mathrm{Dr}$ Vittorio Gentile 2nd University of Naples) or anti-FXIIIa (Behring) were added and incubation continued overnight at room temperature. After the nitrocellulose had been washed three times in TTBS, the appropriate avidin conjugated secondary antibody was added in TTBS for 60 minutes. After washing, immunoreactive proteins were detected by development with the ABC Vectastain kit, according to the manufacturer's directions.

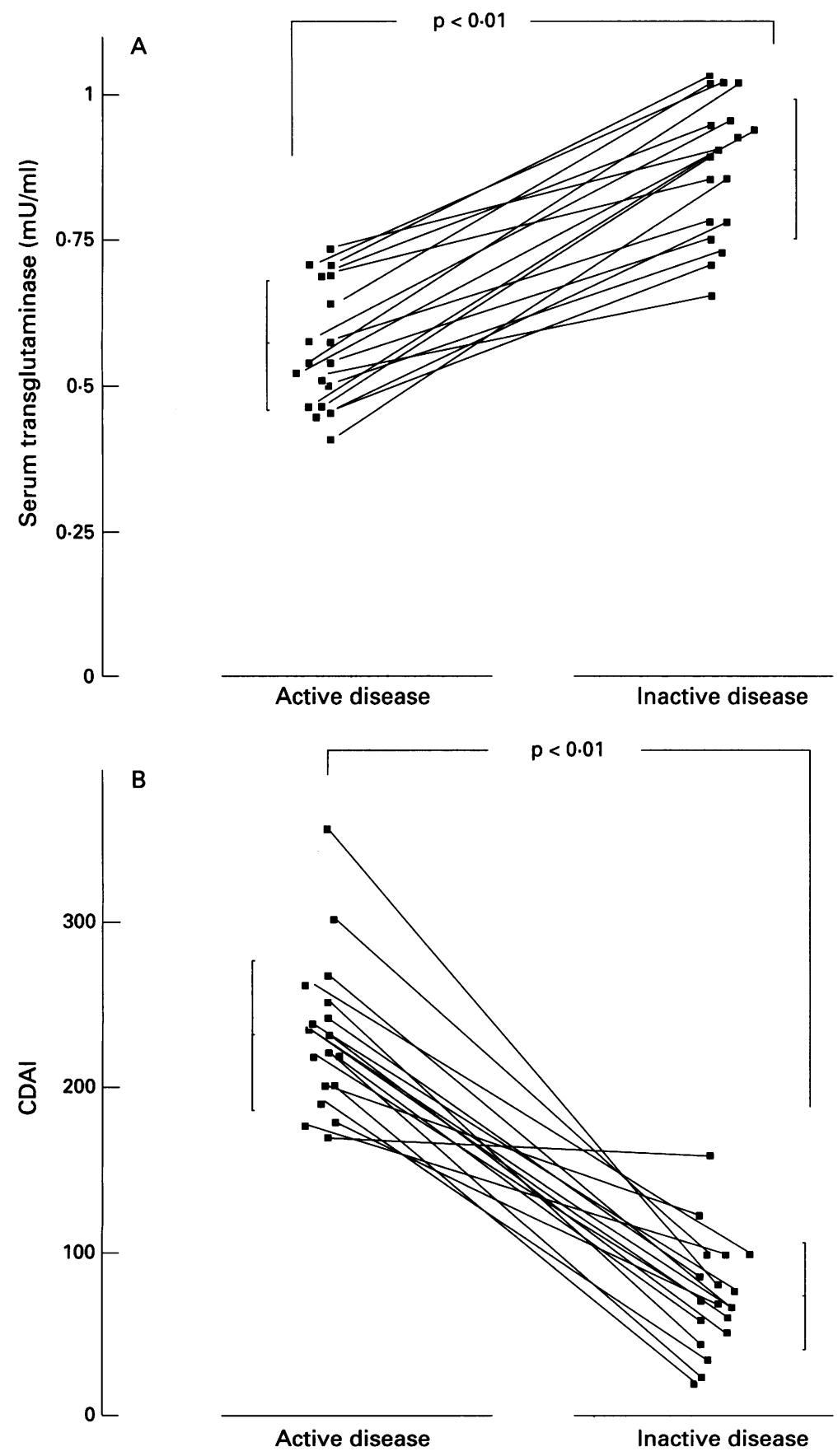

Figure 3: Serum transglutaminase $(A)$ and $C D A I$ score $(B)$ in patients followed up from active into quiescent Crohn's disease.

\section{Immunohistochemistry}

Routinely processed, formalin fixed, and paraffin wax embedded specimens were taken from the ileum of four Crohn's disease patients and from the colon of four Crohn's disease patients who were operated on during 1993 and were drawn from the files of the Institute of Pathologic Anatomy at the School of Medicine, Naples. Uninvolved bowel of patients undergoing surgery for carcinoma or large polyps were used as a 'normal' control tissue. Immunohistochemical examination was performed on normal and abnormal ileum and colon using either anti-tissue transglutaminase or anti-FXIIIa antibodies. The ematoxilineosine stained specimens were immunoprobed with the antibodies and visualised using a peroxidase anti-peroxidase system, ${ }^{29}$ according to the manufacturer's directions.

\section{Statistics}

Student's $t$ test and linear regression were used to perform statistical evaluations. Results, expressed as mean (SD), were considered statistically significant when $\mathrm{p}<0.05$.

\section{Results}

\section{Patients}

Table I shows the clinical and haematological characteristics of Crohn's disease patients. As shown, the mean CDAI score in the total group of patients was 233 (range 169-366), while the mean (SD) serum transglutaminase activity was $0.62(0.11)$. When patients were grouped according to localisation of the disease, serum transglutaminase concentrations were found to be significantly higher in patients with ileitis (transglutaminase $=0.72(0.14) \mathrm{mU} / \mathrm{ml}$ ) compared with patients with ileocolitis/colitis (transglutaminase $=0.50(0.08) ; \mathrm{p}<0.05)$. No differences were found, however, between CDAI scores from patients with ileitis versus ileocolitis/colitis (228 (37) $v 236$ (57) respectively) (Fig 1).

When the whole group of patients was considered, a strong correlation $(r=-0 \cdot 60$; $\mathrm{p}<0.001$ ) was found between serum transglutaminase and CDAI scores (Fig 2). A significant correlation was also found between circulating transglutaminase and serum orosomucoid $(r=-0.55 ; \mathrm{p}<0.01)$ and $\mathrm{C}$ reactive protein $(r=-0.52 ; \mathrm{p}<0.01)$.

Eighteen patients were followed up until remission, which mainly occurred after $4 \cdot 1$ months (range 1-9). Their CDAI scores improved from 230 (46) to 72 (34) during the active and inactive phases respectively $(p<0.01)$. Furthermore, the decreased circulating transglutaminase values seen during the active phase returned toward normal values during the subsequent inactive phase of the disease $(0.61(0.12) v 0.93(0.13), \mathrm{p}<0.01)$ (Fig 3). In the four patients who had intestinal resection, the CDAI significantly decreased 15 days after surgery, while increased serum transglutaminase was seen only at 60 days (Table II). As expected, the mean serum 
TABLE II CDAI and serum transglutaminase ( $\mathrm{mU} / \mathrm{ml}$ ) in patients who had a resection

\begin{tabular}{llcc}
\hline Resection & Before & 15 Days after & 60 Days after \\
\hline CDAI & $265(57) \dagger$ & $64(23)^{\star}$ & $85(31)^{\star}$ \\
Serum transglutaminase & $0.64(0.08) \emptyset$ & $0.74(0.10)$ & $1.05(0.09) \ddagger$ \\
\hline
\end{tabular}

${ }^{\star} \mathrm{p}<0.01 v \dagger ; \neq \mathrm{p}<0.01 v \emptyset$.

enzyme values in the control and healthy volunteer groups fell to within the normal range $(1 \cdot 80(0 \cdot 57) \mathrm{mU} / \mathrm{ml}) .^{7}$

\section{Western blotting}

Antiserum raised against FXIIIa recognised purified FXIIIa and cross reacted with tissue transglutaminase on western blots as shown in Fig 4 (lane 1 and 2). Anti-tissue transglutaminase antiserum showed a specific immunoreactivity for tissue transglutaminase (lane 4), while did not recognise FXIIIa (lane 3).

\section{Immunohistochemical studies}

Tissue transglutaminase antibody - the staining pattern showed that the enzyme is present in the basal region of the crypts in normal ileum (Fig 5 (A)) while strongly positive areas involving the whole crypt and to a lesser extent the extracellular matrix appeared in ileal Crohn's disease (Fig 5 (B)). In normal colon the positivity to tissue transglutaminase antibody was found along the crypt surface (Fig 5 (C)). In colonic Crohn's disease the staining pattern showed that the enzyme is mainly localised to the extracellular matrix but also within the crypts (Fig 5 (D)).

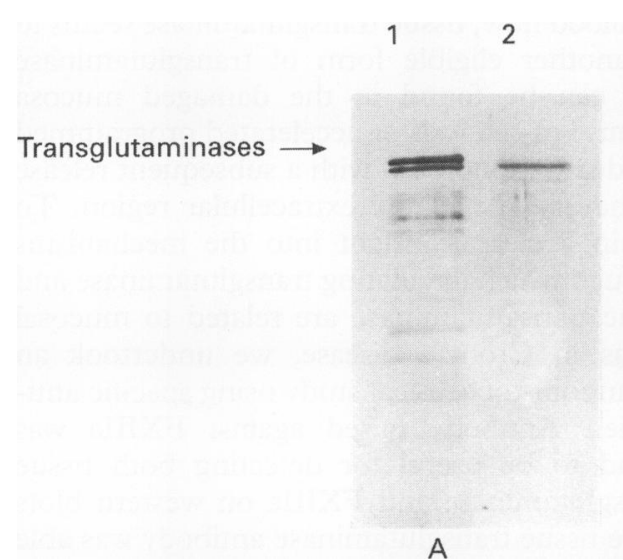

A

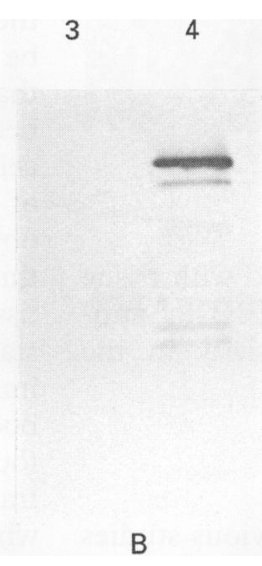

$\mathrm{B}$
Figure 4: Western blots of purified factor XIIIa (lane 1 and 3) and tissue transglutaminase (lane 2 and 4) after denaturing SDS-gel electrophoresis. (A) Blot immunoprobed with factor XIIIa antibody; (B) blot immunoprobed with tissue transglutaminase antibody.

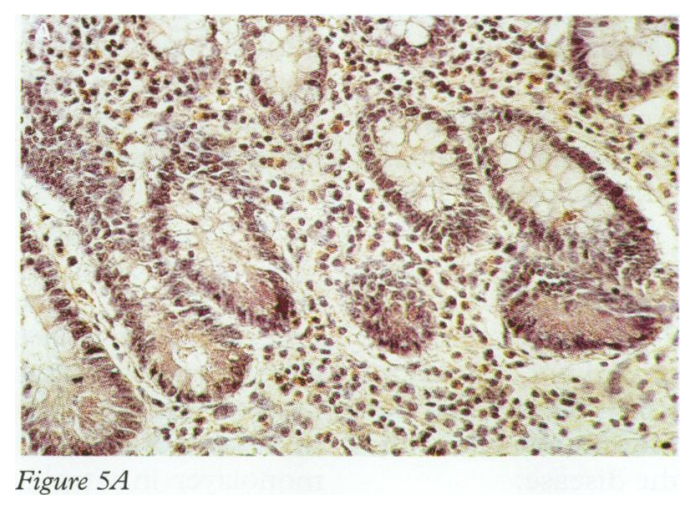

FXIIIa antibody - the positivity to FXIIIa antibody found in normal ileum (Fig 6 (A)) and colon Fig $6(\mathrm{C})$ ) was similar to that obtained with tissue transglutaminase antibody. Immunostaining in ileal (Fig 6 (B)) and colonic (Fig 6 (D)) Crohn's disease showed

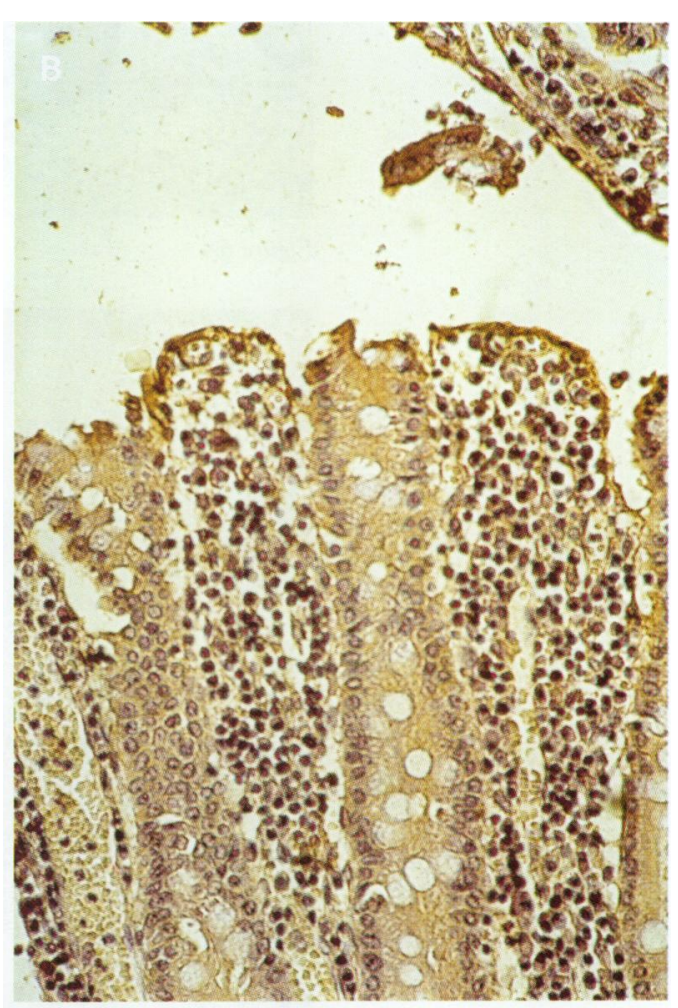

Figure 5B

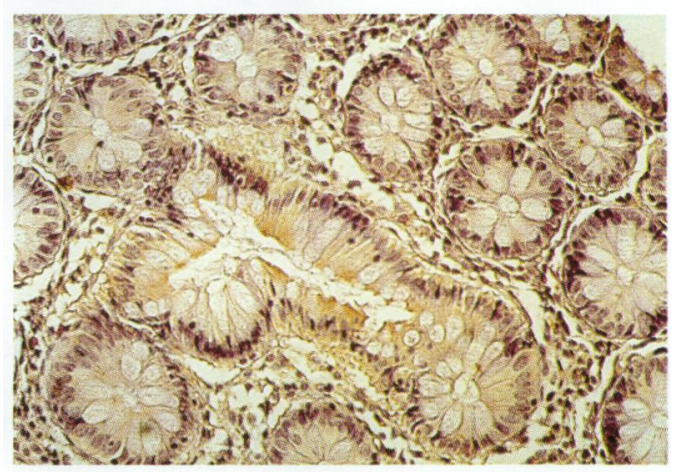

Figure 5C

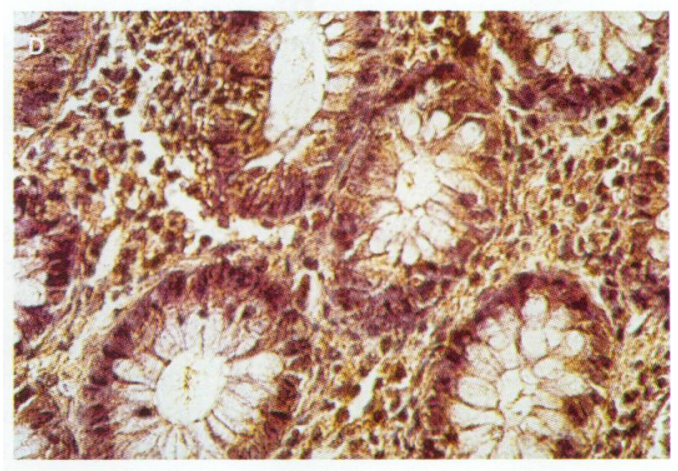

Figure 5D

Figure 5: Immunohistochemistry of specimens from normal controls and Crohn's disease: tissue transglutaminase staining using tissue transglutaminase antibody and peroxidase-antiperoxidase system; (A) normal ileum; (B) Crohn's of the ileum; (C) normal colon; (D) Crohn's of the colon. 


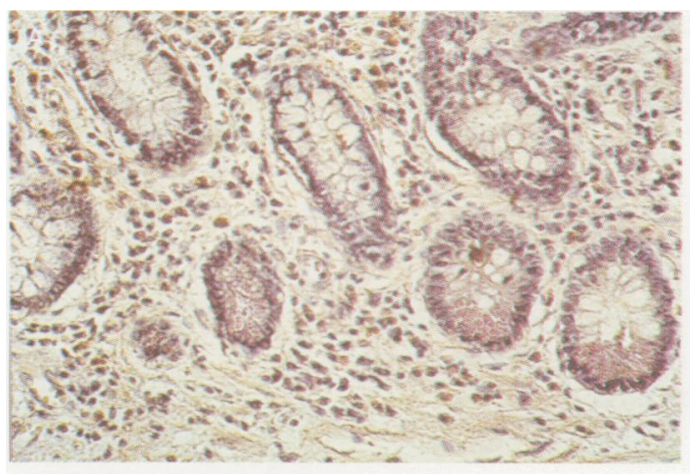

Figure $6 A$

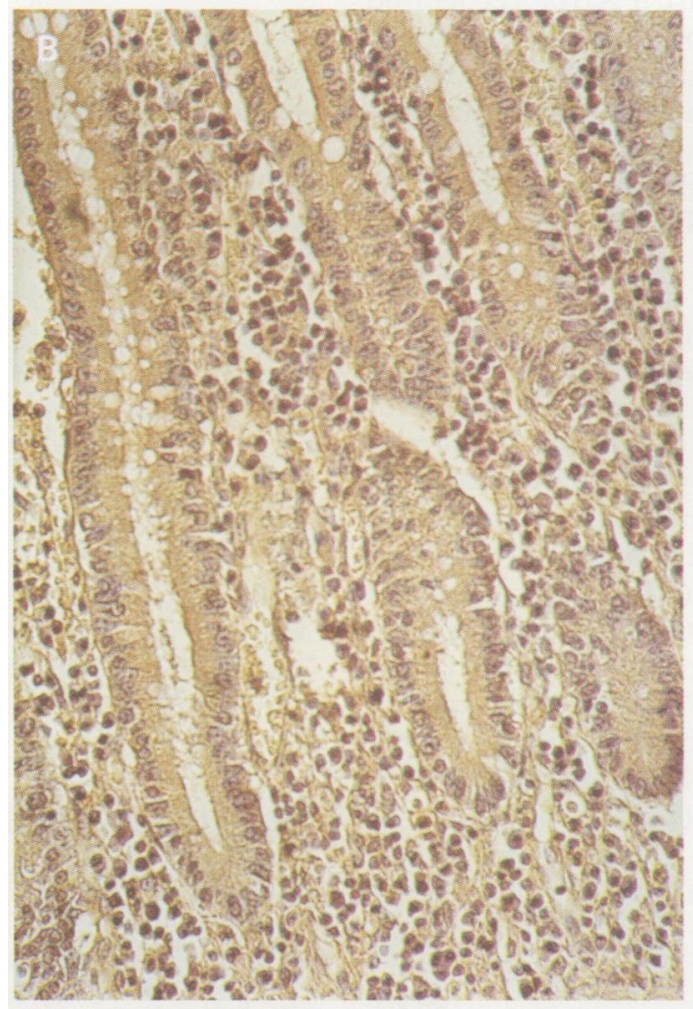

Figure $6 B$

the same pattern of section stained with tissue transglutaminase antibody but FXIIIa antibody produce the highest positivity in the extracellular matrix.

\section{Discussion}

Our data confirm and extend previous studies showing the presence of a correlation between circulating transglutaminase values and Crohn's disease activity as assessed by CDAI score. ${ }^{730}$ A strong correlation was found between serum transglutaminase values and inflammatory mediators as serum orosomucoid and $C$ reactive protein. When patients were followed up, serum transglutaminase values increased during the quiescent phase according to the improved CDAI. Furthermore, patients with ileocolitis/colitis showed serum transglutaminase values lower than the subgroup with ileitis, suggesting that this parameter could be helpful not only in the assessment of the severity of inflammation but also in providing some information about the extension/localisation of the disease.

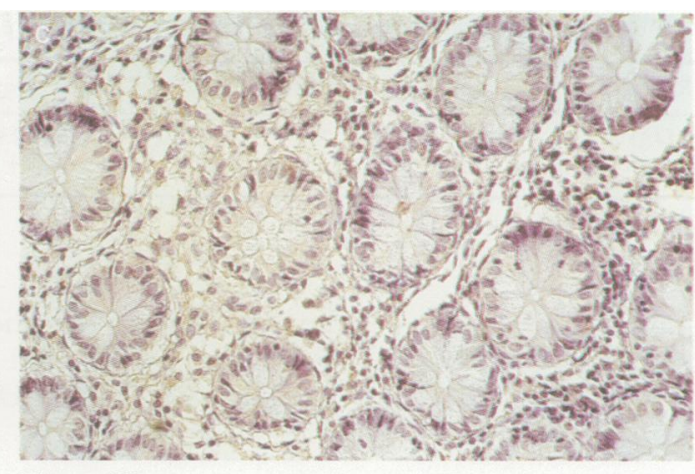

Figure 6C

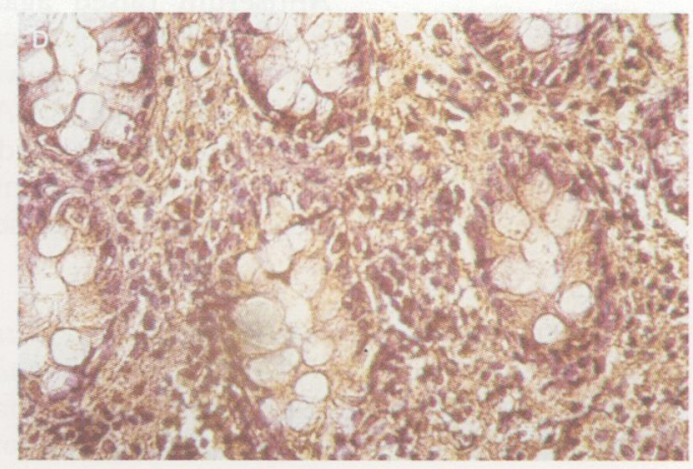

Figure $6 D$

Figure 6: Immunohistochemistry of specimens from normal controls and Crohn's disease: FXIIIa staining using FXIIIa antibody and peroxidase-antiperoxidase system; (A) normal ileum; (B) Crohn's of the ileum; (C) normal colon; (D) Crohn's of the colon.

The decreased serum transglutaminase activity led us to look for a possible enzyme requirement in mucosal recovery. Besides FXIII, which can be delivered to the damaged tissue by the blood flow, tissue transglutaminase seems to be another eligible form of transglutaminase that can be found in the damaged mucosa because of cell lysis or accelerated programmed cell death (apoptosis) with a subsequent release of the enzyme in the extracellular region. To obtain a clearer insight into the mechanisms through which circulating transglutaminase and tissue transglutaminase are related to mucosal status in Crohn's disease, we undertook an immunohistochemical study using specific antibodies. Antibody raised against FXIIIa was found to be useful for detecting both tissue transglutaminase and FXIIIa on western blots while tissue transglutaminase antibody was able to recognise only the protein derived from tissue. These immunoreactivities allowed us to investigate the intestinal pattern of distribution of tissue transglutaminase and FXIIIa both in normal and abnormal mucosa. The same immunostaining pattern was seen in normal tissues using either FXIIIa or tissue transglutaminase antibodies. In Crohn's disease the two antibodies showed a similar staining pattern in the crypts but when FXIIIa antibody was used the highest positivity was detected in extracellular matrix. These findings, for the first time, show the presence of both types of transglutaminases in extracellular matrix of damaged tissues. Tissue transglutaminase activity has been seen in wound healing process in the cell monolayer in vitro ${ }^{10}$ and in mucosal repair in 
the intestine, ${ }^{31}$ using proteins of the extracellular matrix such as fibronectin and collagen, which are suitable substrates for the enzyme. ${ }^{15}$ 3233 On the other hand, it has been suggested that FXIIIa and plasma fibronectin may localise to the extracellular matrix contributing to the healing process. ${ }^{31}$ In 1989 Allan et al ${ }^{34}$ showed that plasma fibronectin concentrations were low in patients with extensive or severe Crohn's disease while increased tissue deposition has been shown in experimental animal models in a variety of circumstances. ${ }^{35}{ }^{36}$ It is probable that plasma transglutaminase (FXIII) in its active form FXIIIa is locally utilised for tissue repair with a subsequent reduced circulating concentration. Recent studies ${ }^{6}$ also showed a significant decrease of FXIIIa in ulcerative colitis suggesting that the enzymatically active fraction plays a part in haemostatic events during the active phase of the disease. We previously showed that transglutaminase activity significantly decreases in serum being closely related to the severity of inflammation in experimental colitis in rats. ${ }^{18}$ In the same model, FXIII intravenous treatment, improved the induced colitis. $^{31}$ These findings show that circulating transglutaminase values are related to the presence of intestinal inflammatory lesions. Even if serum transglutaminase cannot be considered a specific test for the diagnosis of inflammatory bowel disease, our data suggest that serum transglutaminase could represent a very easy test for monitoring the intestinal inflammatory process in Crohn's disease. Patients undergoing bowel resection, showed an improved CDAI 15 days after surgery while serum transglutaminase increased toward control values by 60 days. It is possible that the delayed normalisation of serum transglutaminase when compared with CDAI scores could be related to a slow reconstitution of the normal transglutaminase circulating pool or to the local need of the enzyme for the mucosal morphofunctional recovery after intestinal resection, or both. ${ }^{37}$

In conclusion our data further confirm the usefulness of serum transglutaminase assay as a marker of Crohn's disease activity, extend the utility of serum transglutaminase assay to the follow up of the disease, and underline the role of different types of transglutaminases in the extracellular matrix assembly in the damaged tissue.

The authors thank Dr H Metzner (Behring) for generously providing purified factor XIII and Dr V Gentile (2nd University of Naples) for kindly supplying the tissue transglutaminase antibody.

1 Folk JE. Transglutaminases. Annu Rev Biochem 1980; 49: 517-31.

2 D'Argenio G, Sorrentini I, Cosenza V, De Ritis F, Gatto A Mazzacca G. Transglutaminase and factor XIII in intestinal diseases. Am $\mathcal{F}$ Gastroenterol 1991; 10: 1529-30.

3 Ikura K, Nasu T, Yokota Y, Sasakj R, Chiba H. Amino acid sequence of guinea pig liver transglutaminase from its cDNA sequence. Biochemistry 1988; 27: 2898-905.

4 Floyd EE, Jetten AM. Regulation of type I (epidermal) transglutaminase mRNA levels during squamous dif1989; 9: 4846-51.

5 Folk JE, Finlayson JS. The $\epsilon$ ( $\gamma$ glutamyl) lysine cross-link and the catalytic role of transglutaminases. Adv Protein Chem 1977; 31: 1-133.

6 Standnicki A, Kloczko J, Nowak A, Sierka E, Slwiniski Z. Factor XIII subunits in relation to some other hemostatic parameters in ulcerative colitis. Am $\mathcal{f}$ Gastroenterol 1991; 86: $690-3$.

7 D'Argenio G, Ciacci C, Sorrentini I, Iovino P, Gatto A, Cosenza V, et al. Serum transglutaminase in inflammatory bowel disease. $f$ Clin Gastroenterol 1990; 12: 400-4.
8 Ichinose A, Bottenus RE, Davie EW. Structure of transglutaminases. F Biol Chem 1990; 265: 13411-4

9 Fesus L, Thomazy V, Falus A. Induction and activation of tissue transglutaminase during programmed cell death. FEBS Lett 1987; 244: 104-8.

10 Upchurch HF, Conway E, Patterson MK Jr, Maxwell MD. Localization of cellular transglutaminase on the extracellular matrix after wounding: characteristics of the matrix bound the enzyme. $\mathcal{F}$ Cell Physiol 1991; 1249: 375-82.

11 Birckbichler PJ, Carter HA, Orr GR, Conway E, Patterson MK. $\epsilon$-( $\gamma$-glutamyl) lysine isopeptide bonds in normal and virus transformed human fibroblast. Biochem Biophys Res Commun 1978; 84: 233-7.

12 Multaugh MP, Mehta K, Johnsons J, Myers M, Juliano RL, Davies PJA. Induction of tissue transglutaminase in mouse peritoneal macrophages. F Biol Chem 1983; 258: 11074-81.

13 Barry E, Mosher F. Factor XIII cross-linking of fibronectin at cellular matrix assembly styes. $\mathcal{f}$ Biol Chem 1988; 263: 10464-9.

14 Achyuthan KE, Mary A, Greenberg CS. The binding sites of fibrin(ogen) for guinea pig liver transglutaminase are similar to those of blood coagulation factor XIII: characterization of the binding of liver transglutaminase to fibrin. f Biol Chem 1988; 263: 14296-301.

15 Juprelle-Soret $M$, Wattiaux-de Coninck S, Wattiaux R. Subcellular localization of transglutaminase: effects of collagen. Biochem $\mathcal{\exists}$ 1988; 250: 421-7.

16 D'Argenio G, Sorrentini I, Ciacci C, Spagnuolo $S$ Ventriglia $\mathrm{R}$, De Chiara A, et al. Human serum transglutaminase and coeliac disease: correlation between serum and mucosal activity in an experimental model of rat small bowel enteropathy. Gut 1989; 30: 950-4.

17 D'Argenio G, Sorrentini I, Ciacci C, Mazzacca G. Low serum transglutaminase in patients with intestinal limphoma and $\alpha$-chain disease. Am $\mathcal{f}$ Gastroenterol 1990; 85: 1654-5.

18 D'Argenio G, Sorrentini I, Cosenza V, Gatto A, Iovino P, D'Armiento FP, et al. Serum and tissue transglutaminase correlates with the severity of inflammation in induced
colitis in the rat. Scand $\mathcal{f}$ Gastroenterol 1992; 27: 111-4.

19 Best WR, Beckten JM, Singleton JW, Kern F. Development of the Crohn's disease activity index. Gastroenterology 1976; 70: 439-44.

20 Harvey RF, Bradshaw JM. A simple index of Crohn's disease activity. Lancet 1980; i: 514

21 Modigliani R, Mary JY, Simon JF, Cortot A, Soule JC Gendre JP, et al. Groupe D'etude therapeutique des affections inflammatories digestives. Clinical, biological, and endoscopic picture of attacks of Crohn's disease. Gastroenterology 1990; 98: 811-8.

22 Aimbender E, Cabatu EE, Guzman DM, Sweet AY. Serum C-reactive protein and problems of newborn infants. Pediatr 1982; 101: 438-40.

23 Bienvenu J, Sann L, Bienvenu F, Lahet C, Divry P, Cotte J. Laser nephelometry of orosomucoid in serum of newborn: reference intervals and relation to bacterial infections. Clin Chem 1981; 27: 721-6.

24 Nelson DA. Basic metodology. In: Henry JB, ed. Clinical diagnosis and management by laboratory methods. Philadelphia: WB Saunders, 1979: 858-917.

25 Doumas BT, Watson WA, Biggs HG. Albumin standards and the measurement of serum albumin with bromocresol green. Clin Chim Acta 1971; 31: 87-96.

26 Bruce SE, Bjarnason I, Peters TJ. Human jejunal transglutaminase: demonstration of activity, emzyme kinetics and substrate specificity with special relation to gliadin and celiac disease. Clin Sci 1985; 68: 573-9.

27 Lorand L, Campbell-Wilkes LK, Cooperstein L. A filter paper assay for transamidating enzyme using radioactive amine substrate. Ann Biochem 1972; 50: 623-31.

28 Laemmli UK. Cleavage of structural proteins during the assembly of the head of bacteriophage. Nature 1970;227: $680-5$.

29 Sternberger LA, Hardy PH, Cuculis J, Meyer HG. The unlabeled antibody-enzyme method of immuno-histochemistry. Preparation and properties of soluble antigen-antibody complex (horseradish peroxidaseantihorseradish peroxidase) and its use in identification of spirochetes. $\mathcal{F}$ Histochem Cytochem 1970; 18: 315-9.

30 Hudson M, Wakefield AJ, Hutton RA, Sankey EA, Dhillon AP, More L, et al. Factor XIIIa subunit and Crohn's disease. Gut 1993; 34: 75-9.

31 D'Argenio G, Cosenza V, Sorrentini I, De Ritis F, Gatto A Delle Cave M, et al. Butyrate, mesalamine and factor XIII in experimental colitis in the rat: effects on transglutaminase activity. Gastroenterology 1994; 106: 399-404.

32 Upchurch HF, Conway E, Patterson MK Jr, Maxwell MD. Cellular transglutaminase has affinity for extracellular matrix. In Vitro Cell Dev Biol 1987; 23: 795-9.

33 Lorand L, Daily JE, Turner PM. Fibronectin as a carrier for the transglutaminase from human erythrocytes. Proc Natl Acad Sci USA 1988; 85: 1057-9.

34 Allan A, Wyke J, Allan RN, Morel P, Robinson M, Scott $\mathrm{DL}$, et al. Plasma fibronectin in Crohn's disease. Gut 1989; 30: 627-33.

35 Robbins AB, Doran JE, Reese AC, Mansberger AR. Cold insoluble globulin levels in operative trauma: serum depletion, wound sequestration and biological activity: an experimental and clinical study. Am Surg 1980; 46: 663-72.

36 Reese AC, Doran JE, Callaway BD, Mansberger AR. Sequestration of fibronectin at the site of any injury. $A d v$ Shock Res 1982; 8: 119-27.

37 D'Argenio G, Ciacci C, Sorrentini I, Ventriglia R, Spagnuolo S, Mattera D, et al. Transglutaminase changes in intestinal mucosa after experimental small bowel resection in the rat. Clin Physiol Biochem 1992; 9: 74-7. 